\title{
Infección urinaria gestacional
}

\author{
Antonio Lomanto Morán*; Marcela Lomanto Cardona**; Jacinto Sánchez Angarita***
}

\begin{abstract}
RESUMEN: La mujer embarazada, presenta cambios anatomofisiológicos que predisponen a la I.U.G., en sus diferentes modalidades: cistitis, bacteriuria asintomática y pielonefritis. El manejo de las dos primeras es similar, basándose en esquemas de duración variable con penicilinas, cefalosporinas, sulfonamidas y antisépticos urinarios, asegurando la eliminación de la bacteriuria hasta el final de la gestación, con control seriado de uroanálisis.
\end{abstract}

En caso de pielonefritis, infección urinaria recurrente o anomalía anatomofuncional del tracto genito urinario se indica terapia supresora por lo que resta de la gestación.

PALABRAS CLAVES: Infección urinaria, embarazo, cistitis, bacteriuria asintomática, pielonefritis.

SUMMARY: The pregnant woman presents anatomic and physiological changes that predispose the I.U.G. in its different modalities: cystitis, asymptomatic urinary bacteria and pyelonephritis. The handling of the first two is similar, based on variable time duration schemes with penicillins, cefalosporinas and sulfoamide and urinary antiseptics, assuring the erradication of the urinary bacteria until the end of the gestation period, with serial urinal analysis control.

In case of pyelonephritis, urinary infection recurrent or abnormal anatomical functioning of the genito urinary tract it is advisable to give supresive therapy for the rest of the gestation period.

KEY WORDS: Urinary infection, pregnancy, cystitis, asymptomatic urinary bacteria and pyelonephritis.

\section{Introducción}

Las infecciones bacterianas del tracto urinario ocupan el primer lugar en las mujeres adultas y son la complicación médica más común del embarazo (1-2).

En los últimos años se ha avanzado enormemente en el conocimiento de sus patogénesis, historia natural y tratamiento, pero aún no quedan claros tópicos como la bacteriuria asintomática, las complicaciones obstétricas y si la infección urinaria sintomática lleva complicaciones renales a largo plazo.

La presente revisión condensa los conceptos actuales sobre la infección urinaria y embarazo con especial énfasis en la bacteriuria asintomática, la discusión sobre sus criterios diagnósticos, causas, complicaciones y manejo.

\section{Cambios anatómicos en las vías urinarias durante el embarazo}

La multitud de adaptaciones anatomofisiológicas que ocurren a nivel del tracto urinario incluyen:

\footnotetext{
* Director Científico. Caja de Previsión de Santafé de Bogotá, D.C., Profesor. Departamento de Ginecología y Obstetricia. Facultad de Medicina. Universidad Nacional de Colombia.

** Médico Cirujano. Escuela Colombiana de Medicina.

*** Profesor. Departamento de Ginecología y Obstetricia. Facultad de Medicina. Universidad Nacional de Colombia.
}

- A nivel renal, aumento de la longitud renal en aproximadamente $1 \mathrm{~cm}$, comparada con mujeres sanas no embarazadas (3-4), retornando a los 6 meses del postparto a la normalidad. El mecanismo implicado ha sido el aumento en el flujo sanguíneo y volumen vascular renal.

- Pelvis renal y uréteres: es bien conocido el hidrouréter fisiológico del embarazo. El proceso de dilatación pielouretral comienza durante el primer trimestre y se pronuncia hasta el término, caracterizándose por aumento del diámetro interior del uréter asociado a hipotonía e hipomotilidad muscular más del lado derecho. Como causa de este predominio se incluye el cruce de los vasos ilíacos a nivel del estrecho pélvico superior que ha dado origen al "signo del ilíaco" (Defecto en el llenado ureteral derecho en el punto anatómico descrito).

Otro factor posible, sería la relación de la vena ovárica derecha con el uréter ipsilateral entre L3 y S1, aunque estudios experimentales lo han refutado.

Finalmente el colon sigmoide a la izquierda induciría dextrorotación del útero con la consiguiente comprensión ureteral (5).

Con respecto a la causa del hidrouréter fisiológico hay tres mecanismos implicados: el primero sería la comprensión generada por útero, feto, arteria ilíaca y al conjunto de las venas ováricas, el segundo son los cambios hormonales dados por el aumento de los niveles de progesterona, gonadotrofinas y estrógenos. Basados en estudios in vitro 
las dos primeras disminuirían la contractilidad ureterales, mientras el estrógeno actuaría por estímulo del crecimiento y retención de líquido a nivel intersticial ya que estimula la contractilidad del músculo liso. El tercer mecanismo es el engrosamiento de las paredes del uréter visto descle la séptima semana de gestación y más intensos en la región yuxtavesical del uréter al parecer por efecto hormonal.

- Vejiga: el tono disminuye por efecto progestacional y su capacidad aumenta hasta duplicar su volumen al término de la gestación, la zona del trígono por efecto estrogénico sufre hiperplasia e hipertrofia muscular.

En el segundo y tercer trimestre del embarazo el crecimiento uterino más la hiperemia de los órganos pélvicos desplazan hacia adelante y arriba la vejiga, llegando hacer más abdominal que pélvica. Todo lo anterior facilita el reflujo vesicoureteral (5).

\section{Epidemiología}

Las infecciones de las vías urinarias (IVU) son 14 veces más frecuentes en mujeres que en hombres (6), Stamey las resume así:

- Uretra femenina corta.

- El tercio externo de la uretra es continuamente contaminado por patógenos de la vagina y recto.

- La mujer no evacúa completamente su vejiga.

- La movilización de bacterias a la vejiga con las relaciones sexuales (7).

Durante el embarazo la prevalencia de bacteriuria asintomática según la literatura mundial oscila entre 2.5 y $11 \%$, aunque la mayoría reportan una prevalencia entre el 4 y el $7 \%$ (6). Un estudio colombiano indica $3 \%$ sobre 1238 pacientes en control prenatal en el Instituto Materno Infantil (IMI) y Clínica Fray Bartolomé de las Casas en Santafé de Bogotá (9). Estos valores son aproximadamente los mismos entre mujeres no embarazadas y mujeres sexualmente activas.

Se conocen ciertos factores asociados con la bacteriuria en mujeres, que son los siguientes:

- La edad, la cual aumenta su prevalencia $1 \%$ por cada década de vida a partir de los 5 años de edad.

- La actividad sexual, facilita el movimiento de uropatógenos del introito a la uretra.

- El estado socioeconómico, Turck y cols. hallaron que 6.5 de 557 indígenas tenían bacteriuria durante el embarazo comparadas con sólo $2 \%$ de 1.170 mujeres no indígenas (10) y confirmados posteriormente por otros autores.

- El rasgo de células falciformes en mujeres negras se ha asociado con un incremento del doble de la prevalencia de bacteriuria.

- Factores patogénicos de la bacteria, fimbria o pili en la adherencia, antígeno $\mathrm{k}$ en la actividad antifagocítica, hemolisina en la citotóxica y la resistencia antimicrobiana.

- Diabetes mellitus (7-8).

La importancia de este diagnóstico oportuno se basa en los estudios de Kass en la década de los 50 , quien identificó bacteriuria asintomática persistente en $6 \%$ de pacientes prenatales. La pielonefritis aguda se desarrolló en $40 \%$ de las pacientes que recibieron placebo. Cuando la bacteriuria fue eliminada, la pielonefritis no ocurrió. Además notó tasas de prematuridad y mortalidad neonatal 2 a 3 veces mayores en las cuales la bacteriuria no fue tratada (11-12).

De las mujeres no tratadas con infección urinaria baja no complicada, el 50-70\% no tendrán síntomas y los cultivos de orina serán estériles en el término de un mes (35).

\section{Etiopatogenia}

La mayoría de los organismos responsables de las infecciones de vías urinarias se consideran parte de la flora fecal normal, de allí que se reporte Escherichia coli en 80-90\% de los estudios bacteriológicos en la literatura (73.3\% estudio IMI) (9). En segundo lugar Klebsiella, Proteus sp, Enterobacter sp y Pseudomonas, aunque algunos informes implican el Staphilococcus saprophiticcus con prevalencia del $10-20 \%$ (13).

Este microorganismo es más agresivo que el E. coli y algunos estudios muestran incidencia de 41-51\% de ataque a las vías urinarias superiores, a diferencia del $16 \%$ observado con E. coli (35).

El S. saprophiticcus tiene mayor propensión a causar infecciones recurrentes y persistentes de las vías urinarias.

Otros microorganismos reportados en cultivos como Ureoplasma urealiticum, lactobacilos y Streptococcus microaerófilos han aumentado los reportes de bacteriuria a cifras del $25 \%$, pero su papel patógeno aún no se ha aclarado completamente (14).

En caso de no haber bacteriuria significativa puede detectarse Clamydia en $34 \%$ de mujeres con síntomas de infección urinaria. Esta infección se acompaña de piuria (Def: Presencia de 8 leucocitos o más por campo de amplificación en una muestra de orina centrifugada (35).

Las bacterias pueden penetrar a las vías urinarias por vía ascendente, descendente o hematógena o por conductos linfáticos.

- Vía ascendente: Implica la migración de las bacterias a través de la uretra, desde el área periuretral a la vejiga y porción superior de las vías urinarias o por la implantación directa que puede surgir durante la instrumentación.

- Vía descendente o hematógena: se hace por siembra hematógena de bacterias, facilitada por el gran volumen de sangre que fluye en la zona (20-25\% del gasto cardíaco) en combinación con la elevada presión hidrostática intracapilar. La médula renal que recibe el $25 \%$ del flujo sanguíneo es más susceptible a la infección que la corteza que recibe el $75 \%$ de éste.

- Vía linfática: se ha demostrado interconexión de los conductos linfáticos entre el intestino grueso y las vías urinarias pero no se han aclarado su significado clínico.

Con respecto a los mecanismos de defensa el más eficaz es el recambio de las células epiteliales y los efectos de "arrastre" de la micción. La flora bacteriana normal del introito vaginal, la región periuretral y la uretra pueden interferir en la unión de uropatógenos por bloqueo espacial, por competencia, por sitios receptores e inhibición de la proliferación bacteriana. Los lactobacilos que son parte de la flora vaginal normal se adhieren a las células uroepiteliales e inhiben la fijación de E. coli, K. pneumoniae, pseudomonas y aminoran la unión de la Candida albicans. 


\section{Clasificación y diagnóstico}

La infección urinaria denota colonización microbiana de la orina e invasión de las vías urinarias superiores, inferiores o ambas.

La IVU podemos dividirla de la siguiente forma:

Cistitis

Pielonefritis

Bacteriuria asintomática

- Cistitis: (C) Inflamación superficial de la mucosa vesical que se caracteriza clínicamente por la disuria, urgencia, polaquiuria, nicturia, molestias suprapúbicas y con menor frecuencia hematuria e incontinencia urinaria.

- Pielonefritis: (P) Representa la infección bacteriana del parénquima renal junto con la posibilidad de la lesión grave de los riñones a largo plazo. La podemos subdividir a su vez en:

Pielonefritris aguda: (PA) Infección piógena activa que puede acompañarse de fiebre, escalofríos, dolor en el costado, dolor en el ángulo costovertebral a la palpación, náuseas, vómito y otras manifestaciones. Pueden persistir síntomas de cistitis o ser los únicos signos evidentes, dificultando el diagnóstico diferencial.

Pielonefritis crónica: (PC) Las manifestaciones principales son causadas por la lesión sufrida ên infecciones previas y se les clasifica en activas e inactivas. La pielonefritis crónica activa aparece en mujeres con infecciones complicadas persistentes cuyo diagnóstico se basa en el hallazgo de infección asociada a defectos neurológicos de la micción (Neuropatía por reflujo, vejiga tónica) más la presencia de un cuerpo extraño como cálculo, sutura, sonda o una nefropatía intrínseca (Diabética o poliquística).

La pielonefritis crónica inactiva denota cicatrices estériles focales de una infección anterior. Desde el punto de vista histológico se caracteriza por nefritis intersticial dispersa y zonal, destrucción tubular, infiltrado celular y cambios inflamatorios crónicos del parénquima renal (35).

- Bacteriuria asintomática: (BA) Investigación original de Kass (15), se definió como el aislamiento de un solo uropatógeno en dos muestras consecutivas de orina que contuviesen más de $100.000 \mathrm{UFC} / \mathrm{ml}$ del mismo microorganismo, en la primera orina de la mañana a mitad del chorro, obtenidas con técnica limpia. Este concepto sin modificaciones hasta años recientes muestra una alta especificidad (0.99) pero baja sensibilidad (0.51) en detectar bacteriuria. Se ha propuesto por Stamm y cols. un nuevo criterio diagnóstico en mujeres con disuria aguda (16). Ellos notaron que $30-50 \%$ de pacientes con infección del tracto urinario bajo en forma aguda caracterizado por disuria, urgencia y frecuencia no superaba el criterio 100.000 UFC/ $\mathrm{ml}$ para infección, pero si tenía bacilos gram negativos aerobios patógenos a la punción suprapúbica. Este nuevo criterio $100 \mathrm{UFC} / \mathrm{ml}$ tendría una sensibilidad de 0.95 y especificidad de 0.85 y un alto valor predictivo 0.88 entre mujeres sintomáticas (17).

Aunque no hay consenso en el momento, si es claro que muchas mujeres sintomáticas consideradas no infectadas según el criterio tradicional, en efecto tienen bacteriuria con o sin infección subclínica del tracto urinario superior.
El rango de 100 a $100.000 \mathrm{UFC} / \mathrm{ml}$, ha sido usado como criterio significativo en pacientes cateterizados, ya que un estudio de ellos demostró que estos conteos de colonias, si no se tratan casi todos llegarán a superar las 100.000 UFC/ $\mathrm{ml}$ en $72 \mathrm{~h}$, sugiriendo que estos bajos conteos, representan verdadera bacteriuria vesical (17).

Otro aspecto no tratado en la literatura, es el referente al valor real de bacteriuria que puede aceptarse posterior al tratamiento. No es claro si valores inferiores a 100.000 UFC/ml en pacientes asintomáticos post-tratamiento, tiene el mismo significado de aquél en los asintomáticos en cultivos de rutina.

Si el conteo inicial fue "bajo" (>100 pero < 100.000) es razonable pensar que un valor igual post-tratamiento sea inaceptable (13). Por último mencionar que la piuria puede ser una prueba de tamizaje útil, ya que está presente en más del $95 \%$ de las mujeres con IVU sintomática incluyendo los "bajos" conteos y está ausente en la mayoría de los que no tienen IVU o enfermedades sexualmente trasmitidas (18) aunque nunca equiparable al cultivo urinario.

Otros intentos de correlación clínica más económica como identificar una o más bacterias a gran aumento en una muestra de orina no centrifugada, no es lo suficientemente sensible para recomendarla en la práctica clínica (19), igual sucedió que con la prueba de nitritos (20).

Caso opuesto parece ser las pruebas semicuantitativas de "Kits" comerciales que pueden ser usados en el consultorio y que recomienda Andriole recientemente (14), tomando en cuenta todas las precauciones en la toma de la muestra.

No se recomienda de ninguna manera la toma de muestras urinarias con catéter en la mujer embarazada, ya que hay un riesgo de 4-6\% de introducir la infección, más aún, teniendo en cuenta la predisposición que existe en la gestación.

La punción suprapúbica sería ideal, aunque ha demostrado ser segura durante el embarazo, no se emplea corrientemente y se reserva para casos especiales (21).

\section{Complicaciones relacionadas con la bacteriuria asintomática}

\section{A. Maternas}

1. Pielonefritis: Como ya vimos previamente es la complicación mejor descrita y asociada con la bacteriuria asintomática (11-12).

Basados en datos obtenidos usando diferentes métodos para localizar el sitio de la infección, parece que entre el 25$50 \%$ de las mujeres embarazadas con BA tienen compromiso del tracto urinario superior (22).

Las pacientes que no responden satisfactoriamente a la terapia antimicrobiana convencional, son un subgrupo con alto riesgo de desarrollar pielonefritis durante el embarazo.

La predisposición a la pielonefritis se entiende fácilmente con los cambios anatómicos ya revisados y a nivel fisiológico debemos recordar que el $\mathrm{pH}$ urinario aumenta, así como la aminoaciduria y glucosuria, lo cual crea un medio propicio para la multiplicación bacteriana.

La era preantibiótica demostró la asociación entre la pielonefritis aguda del embarazo y el parto pretérmino con 
frecuencia de $20-50 \%$ (23-24) corroborados en épocas recientes por múltiples autores. Varios mecanismos han sido postulados para esta asociación: Los pirógenos generados causarían incremento de la actividad miometrial y uretéricas resultando contracciones miometriales reflejas. La endotoxina de los organismos Gram negativos a menudo asociada con pielonefritis, puede tener un efecto semejante a la oxitocina sobre el miometrio, y la endotoxina de los Gram negativos puede en efecto atravesar la placenta y producir parto prematuro (24).

2. Anemia: Hay tantos estudios en favor y en contra de la asociación bacteriuria/anemia. Se ha tratado de implicar el estado socioeconómico, enfermedad renal subclínica sin llegar a nada en concreto, por lo cual en la actualidad esta relación permanece en debate (36).

3. Hipertensión: Kincaid-Smith y Bullen reportaron una incidencia incrementada tanto de preeclampsia como hipertensión en pacientes con BA durante la gestación. Aunque esto puede ser reflejo de enfermedad renal subyacente, en un grupo de pacientes no hallaron cambios en la hipertensión con el tratamiento de la bacteriuria (25). Esta asociación es bastante cuestionable.

4. Enfermedad renal crónica: Se ha sugerido que un pequeño grupo bien definido de mujeres embarazadas con pielonefritis, eventualmente desarrollaría enfermedad renal terminal, el riesgo exacto no es conocido. Cambios radiográficos sugiriendo pielonefritis crónica se observan entre $14-27 \%$ de mujeres en evaluaciones posteriores luego de la detección de bacteriuria durante el embarazo.

En síntesis el embarazo pone de manifiesto pacientes con riesgo de desarrollar condiciones subyacentes (enfermedad parenquimal renal, cálculos, anomalías del tracto urinario y dilatación uretérica) que per se no son causados por la gestación y que deben ser manejados para evitar la progresión a enfermedad renal crónica (36).

\section{B. Fetales}

1. Parto pretérmino: Está claramente establecida esta asociación entre pielonefritis aguda y parto pretérmino pero directamente la BA con éste aún es debatido, la mayoría de estudios no encuentran esta asociación (7).

Faltan aún estudios de cohorte con controles para aclarar definitivamente este punto.

Aún más discutido es si el tratamiento de la BA disminuye de forma substancial el parto pretérmino, muchos apoyan esta posición (7), pero hay muchas variables de confusión que deben ser corregidas (Estado socioeconómico, unidad en el criterio de prematuridad) para llegar a conclusiones válidas.

El mecanismo por el cual la infección sintomática causaría el parto pretérmino no es del todo clara, involucraría en parte microorganismos productores de fosfolipasa A2 (FL A2), la cual actúa liberando ésteres del Ac Araquidónico de los fosfolípidos de las membranas que a su vez produciría PGE2 y PGF2 con "inducción" espontánea del parto. Estas prostaglandinas producen maduración cervical, dilatación y las contracciones uterinas (26).

Muchas bacterias incluyendo E. coli y otras Gram negativas pueden producir FLA2 sirviendo como gatillo el mecanismo ya expuesto. El lactobacilo, la bacteria más común que habita en el tracto genitourinario bajo materno tiene muy bajos niveles de actividad de la fosfolipasa A2, mientras tres de las cinco especies bacterianas con los niveles más altos de actividad de la fosfolipasa A2 (B. fragilis y especies de peptostreptococos) reemplazan al lactobacilo cuando se desarrolla vaginitis (36).

Hay evidencia de que las bacterias pueden diseminarse al líquido amniótico desde el tracto urinario, dando amnionitis y parto pretérmino (26-27).

2. Bajo peso al nacer: Los estudios son contradictorios, aún falta aclaración. Un reciente estudio de casos y controles en aborígenes australianos apoyan esta hipótesis (28).

3. Pérdidas fetales, infección fetal y anomalías congénitas: Varios estudios han llamado la atención sobre la muerte fetal y/o abortos en mujeres embarazadas con bacteriuria aunque otros lo anotan.

Kincaid-Smith y Bullen notaron este aumento en la frecuencia de abortos pero no pudieron probar que el tratamiento de la bacteriuria disminuyera dichos valores (25).

Con respecto a las malformaciones congénitas, Patrick notó incidencia aumentada de defectos de fusión de la línea media dorsal en los hijos de mujeres con BA (29). Otros apoyan estos hallazgos pero falta aún investigación (25-30).

\section{Tratamiento}

El tratamiento ideal debe incluir las siguientes características:

- Efecto mínimo en la flora fecal y vaginal

- Espectro antimicrobiano adecuado

- Alta concentración urinaria

- Baja concentración en sangre

- Mantener la terapia en forma breve y no tóxica

- Guiada por sensibilidad antimicrobiana

- Bajo costo

El embarazo genera cambios a nivel farmacocinético y farmacodinámico de los antibióticos usados en la terapia de la infección vías urinarias, así:

-Renal: El flujo sanguíneo y la tasa de filtración glomerular aumentadas en un 50\% después del 40 . mes genera una rápida depuración de los medicamentos que a su vez conlleva concentraciones subterapéuticas pudiendo ser necesario incrementar la dosis o reducir el intervalo entre dosis.

-Volumen: Cuyo incremento es del $50 \%$ al 80 . mes, aumenta el volumen de distribución y reduce la concentración de proteínas plasmáticas, siendo necesario dosis de carga más grande o subvalorar el nivel sérico de droga activa.

-Metabólica: El metabolismo hepático incrementado activado por progesterona aumenta la biotransformación y por supuesto obtener concentraciones subterapéuticas, necesitando aumento de las dosis o la frecuencia de administración.

-Gastrointestinal: La demora en el vaciamiento gástrico y el tránsito intestinal reducen la absorción a nivel de intestino delgado pero se aumenta en forma global a nivel del tracto gastrointestinal haciendo impredecible la absorción oral del medicamento. 
-Placentarios: A medida que se incrementa la gestación, se adelgaza la barrera fetomaterna con incremento progresivo de la difusión transplacentaria obteniéndose concentraciones subterapéuticas.

El efecto neto de estos cambios es la disminución de la concentración sérica de los antibióticos, pero cuando se utilizan antibióticos como penicilinas, cefalosporinas o nitrofurantoína para el manejo de I.V.U., estos factores no influyen significativamente ya que son excretados principalmente por la orina.

Las drogas actualmente usadas en el embarazo para el tratamiento de la I.V.U. incluyen:

\section{-Penicilinas:}

Amoxicilina

Ampicilina

Amoxicilina/Ac. clavulánico

\section{-Cefalosporinas:}

\section{Cefalexina}

\section{-Sulfonamidas:}

\section{Sulfisoxasol}

\section{-Antisépticos urinarios:}

Nitrofurantoína.

Se encuentran contraindicados TMP-SX porque puede causar vasculitis a la madre y en feto anomalías congénitas y antagonismo del folato.

El sulfisoxasol no debe darse cerca al término del embarazo por el riesgo de Kernicterus en el feto y hemólisis en caso de deficiencia de glucosa 6-fosfato deshidrogenasa, esto último también válido para la nitrofurantoína que en la madre puede causar neumonía intersticial y neuropatía (8).

Los aminoglucósidos rara vez se indican en el tratamiento de la cistitis o bacteriuria asintomática y debe reservarse para casos de pielonefritis o resistencia bacteriana.

Para el manejo adecuado y oportuno de la I.V.U. se debe realizar un tamizaje con urocultivo a toda mujer en la primera visita prenatal, preferiblemente en el primer trimestre.

En mujeres con historia de I.V.U. a repetición, tienen más alto riesgo de desarrollar infección al final de embarazo, a pesar de tener urocultivos negativos, se deben realizar al iniciar el tercer trimestre (14).

El seguimiento con urocultivo debe hacerse una semana después de iniciar la terapia, si éste es estéril, se continuará con control mensual hasta el parto.

En caso de falla en el tratamiento, que se puede hasta en 20-30\% (14), se repite el tratamiento con otro antibiótico, ojalá basado en antibiograma.

Llama la atención en el estudio del IMI que la mayor sensibilidad de los microorganismos fue a los macrocristales de nitrofurantoína (87\%), seguidos por las cefalosporinas $(55 \%)$ y que la recidiva de infección fue muy baja (9).

En pocos casos no hay respuesta a dos tratamientos consecutivos. La conducta es guiarse por antibiograma hasta suprimir la bacteriuria continuando terapia supresora por lo cual se ha propuesto:
- Nitrofurantoína 50-100 mgs en la noche hasta el parto.

- Sulfisoxasol $500 \mathrm{mgs} \mathrm{c} / 12$ horas.

- Ampicilina $250 \mathrm{mgs} \mathrm{c} / 12$ horas.

Esta medicación se continúa hasta el final del embarazo y debe descartarse enfermedad o anomalía renal subyacente $(8,14,22)$.

\section{Tratamiento de la cistitis y la bacteriuria asintomática}

Su manejo es el mismo en la práctica, se han propuesto clásicamente tratamientos de 7-10 días aunque en los últimos años varios investigadores han reportado resultados favorables usando tratamientos mucho más cortos, entre ellos monodosis y de tres días. 37).

Terapias de 7-10 días: Efectividad entre 70-98\% (14,

Droga Dosis

Ampicilina $\quad 250-500 \mathrm{mg}$. $\mathrm{c} / 6 \mathrm{~h}$

Amoxicilina $250 \mathrm{mgs}$. c/6 h

Amoxicilina/Ac. clavulánico 250/125 mgs. c/8 h

Cefalexina 250-500 mgs. c/6 h

Sulfisoxasol 1 gr. seguido por $0.5 \mathrm{gr}$. $\mathrm{c} / 6 \mathrm{~h}$

Nitrofurantoína $\quad 50-100 \mathrm{mg}$. c/6 h

Terapia de tres días: Efectividad de $94 \%$ (37).

Nitrofurantoína $\quad 100 \mathrm{mg} . \mathrm{c} / 6 \mathrm{~h}$

Amoxicilina $500 \mathrm{mg}$. $\mathrm{c} / 8 \mathrm{~h}$.

Monodosis: Efectividad del 50-80\% (14, 7, 37).

Ampicilina $2 \mathrm{gr}$.

Amoxicilina $2 \mathrm{gr}$.

Cefalexina 2 gr.

Sulfisoxasol $2 \mathrm{gr}$.

\section{Indicaciones de la monodosis}

- Mujer no embarazada

- Bacteriuria asintomática

- Cistitis bacteriana aguda

- Infección no complicada

\section{Contraindicaciones de la monodosis}

- Pielonefritis

- Anormalidades estructurales o funcionales conocidas

- Empleo de sondas a permanencia

- Embarazo e infecciones recurrentes no tratadas

\section{Ventajas de la monodosis}

- Llega a la mucosa vesical en mayor concentración

- Excelente cumplimiento

- Disminución de costos

- Disminución de los efectos adversos (34)

Con base en los datos expuestos el tratamiento de 10 días es más efectivo que las monodosis y no parece existir diferencia significativa con el tratamiento de 3 días. Al momento actual sea cual sea el esquema usado, lo importante es documentar la eliminación de la bacteriuria $(14,32-$ 34). 


\section{Tratamiento de la pielonefritis}

Por sus posibles riesgos y complicaciones debe ser de manejo intrahospitalario asegurando la vía intravenosa para hidratación y manejo antibiótico. Esta se mantiene por 14 días cambiando a vía oral según respuesta clínica.
Los esquemas propuestos son:

- Ampicilina 2 gr IV c/6 h

- Cefazolina 1-2 gr IV c/8 h

- Gentamicina 3-5 mg/kg/día IV dividido en tres dosis.

\section{BIBLIOGRAFIA}

1. Sanford JP. Urinary tract symptons and infection. Annu. Rev. Med. 1976; 26: 485-498.

2. Andriole VT. Urinary tract infections in pregnancy. Urol. Clin. North. Am. 1975; 2: 485.

3. Hodson CJ. Radigraphic kidney size. In: Black Dak, ed. Renal disease. Oxford: Blackwell Scientific publications, 1968; 136.

4. Bailey RR., Rolleston GL. Kidney length and ureteric dilatation in the puerperium. J. Obstet. Gynecol. Br. Commonw 1971; 78: 55.

5. Samir NB. Cambios morfológicos en las vías urinarias durante el embarazo. Clin. Obstet. Gynecol. 1985; 2: 307-316.

6. Sweet RL. Bacteriuria and pyelonephritis during pregnancy. Semin perinatol 1977; 1: 25-40.

7. Sweet RL., Gibbs RS: Urinary tract intection. Infectious diseases of the female genitals tract. Secondedition. 1991; 267-289.

8. Mc Nealey SG. Treatment of urinary tract infection in pregnancy. Clin. Obstet. Gynecol 1988; 31: 480-487.

9. Lomanto AM., Sánchez JA., Lomanto AC. Bacteriuria Asintomática en el embarazo. Revista Colombiana de Obstetricia y Ginecología. Vol. XLI No. 1, 1988; 13-23.

10. Turck M., Goffe BS and Petersdorf RG. Bacteriuria of pregnancy. Relation to socioeconomic factors. N. Engl. J. Med. 1962; 266: 857860.

11. Kass EH. The role of asymtomatic bacteriuria in the pathogenesis of pyelonephritis. In Quinn RL, Kass EH. (eds). Biology of pyelonephritis. Boston, Little Brown, 1960; 399-412.

12. Kass EH. Bacteriuria and pyelonephritis of pregnancy. Arch. Intern. Med. 1960; 205: 194-198.

13. Hooton TM. The epidemiology of urinary tract infection and the concept of significant bacteriuria. Infection 18 (1990) Supp. 12 pp. 540-543.

14. Andriole VT., Patterson TF. Epidemiology, natural history, and management of urinary tract infections in pregnancy. Med. Clin. North. Am. Vol. 75, No. 2 March 1991; 359-373.

15. Kass EH., Finland M. Asymtomatic infections of the urinary tract. Trans. Assoc. Am. Phys. 1956; 69: 56-64.

16. Stamm WE., Counts GW., Running KR., Fihn S., Turck M., Holmes KK. Diagnosis of coliform infection in acutely dysurit women. N. Engl. J. Med. 1982; 307: 463-468.

17. Stark RP., Maki DG. Bacteriuria in the cathetherized patient what quantitative level of bacteriuria is relevant? N. Engl. J. Med. 1984; 311: 560-564.

18. Stamm WE. Measurement of pyuria and its relation to bacteriuria. Am. J. Med. 75 (Suppl. 1B) 53-58.

19. Norden CW., Kass EH. Bacteriuria of pregnancy: critical pparaisal. Ann. Rev. Med. 1968; 19: 431.

20. Lenke RR., Van Dorsten JP. The efficacy of the nitrite test and microscopic urinalisis in predicting urine culture result Am. J. Obstet. Gynecol. 1981; 140: 427.
21. Hamilton-Miller JMT., Brooks SJP., Brumfitt W et al. Screening for bacteriuria: Microstix and dipslides. Postgrad Med. J. 1977; 53: 248.

22. Krieger JN. Complications and treatment of urinary tract infections during pregnancy. Urologic Clinics of North American 1986; 13(4): 685-693.

23. Baird $\mathrm{D}$. The upper urinary tract in pregnancy and the puerperium with special reference to pyelitis of pregnancy. J. Obstet. Gynecol. Br. Emp. 1936; 43: 1-59.

24. Dodds GH. Bacteriuria in pregnancy, labor and puerperium. J. Obstet. Gynecol. Br. Emt. 1931; 38: 773-787.

25. Kincaid-Smith-Bullen, M. Bacteriuria in pregnancy. Lancet 1965; 1: 395-399.

26. Bejar R., Curbelo V., Davis C. Premature labor II. Bacterial sources of phospholipase. Obstet. Gynecol. 1981; 57: 479.

27. Naeye RL. Causes of the excessive rates of prenatal mortality and prematurity in pregnancies complicated by maternal urinary tract infections. N. Engl. J. Med. 1979; 390: 819.

28. Schultz R., Read AW., Straton JAY et al. Genitourinary tract infections in pregnancy and low birth weigh: case-control study in Australian Aboriginal women. BMJ 1991; 303: 1369-1373.

29. Patrick MJ. Renal infection in pregnancy. The natural development of bacteriuria in pregnancy. J. Obstet. Gynecol. Br. commonw 1966; 73: 793-796.

30. Savage WE., Hajj SH., Kass EH. Demographic and prognostic characteristics of bacteriuria in pregnancy. Medicine (Baltimore) 1967; 46: 385-407.

31. Zhanel GG., Harding GKM., Guay DRP. Asynmptomatic Bacteriuria: Which patients should be treated? Arch. Intern. Med. 1990; 150 1389-1396.

32. Bailey RR. Single-dose antibacterial treatment for bacteriuria in pregnancy. Drugs 1984; 27: 183.

33. Brumfitt W., Hamilton-Miller JMT., Franklin INS. Conventional and two-dose amoxycillin treatment of bacteriuria in pregnancy and recurrent bacteriuria: A comparative study. J. Antimicrob Chemother 1982; 10: 239.

34. Harris RE., Gilstrp LC., Pretty A. Single-dose antibacterial therapy for asymptomatic bacteriuria during pregnancy. Obstet. Gynecol. 1982: 59: 546.

35. Clínicas de Ginecología y Obstetricia: Temas actuales. Urología ginecológica. 1989; 4: 892-910.

36. Summary of a workshop on Maternal Genitourinary Infections and the Outcome of Pregnancy. The Journal of Infectious Diseases 1983, 147(3).

37. Pedersen ES., Blakstad M., Bergan T. Bacteriuria in the puerperium. Am. J. Obstet. Gynecol. 1990; 162: 792-797. 